\title{
AN OVERVIEW OF CLOUD COMPUTING FOR E-LEARNING WITH ITS KEY BENEFITS
}

\author{
Mansi Bosamia and Atul Patel \\ Smt. Chandaben Mohanbhai Patel Institute of Computer Applications (CMPICA), \\ Charotar University of Science and Technology (CHARUSAT), Changa-Anand, \\ GUJARAT, India.
}

\begin{abstract}
Education is a necessary human virtue and essential for society because it reflects the personality of the human being in our society. The effective way of teaching gives the quality of education and advance learning such as e-learning to the learners and also a high quality of teaching to the tutors. Information Technology (IT) plays a significant role in field of education. Now days, E-learning and M-learning have become very popular trends of the education technology riot. E-Learning is the new tool related to the virtualized distance learning by means of electronic communication mechanisms, specifically the Internet to enhance the traditional learning system. An E-learning system generally needs a lot of software and hardware resources. Today, many educational institutions cannot afford such investments and environments therefore cloud computing is the finest solution. The Cloud Computing environment rises swiftly as a natural platform to provide support to e-Learning systems. Hence, this paper presents the impact on using cloud computing for e-learning which contains an innovative environment resulting from both virtual and personal learning environments. This paper introduces concepts of e-learning and cloud computing infrastructure with their key benefits.
\end{abstract}

\section{KEYWORDS}

E-learning; M-learning; Cloud computing; Software as a services (SaaS); Infrastructure as a services (IaaS); Platform as a services (PaaS); EdTech.

\section{INTRODUCTION}

Education plays a vital role in our success in the personal growth. The more we learn the more we grow. Education helps us with many things like make powerful an individual to think, question and see away from the obvious. Education is the best way to gratify our curiosity and desire to learn more. Educational technology, sometimes termed as EdTech, is the study and ethical practice of facilitating E-learning, which is the learning and improving performance by creating, using and managing appropriate technological processes and resources ${ }^{[1]}$. E-Learning supports electronic communication mechanisms with Information and Communication Technology through the Internet. Now a day, government is prompting educational courses to make our nation's youth very efficient, intelligent, knowledgeable and capable. 
International Journal of Information Sciences and Techniques (IJIST) Vol.6, No.1/2, March 2016

\section{E-LEARNING}

E-Learning is electronic learning, think instead of a big " $E$ " for "exciting, energetic, engaging, extended" learning ${ }^{[2]}$. E-learning is a new education concept by using the Internet technology, it deliveries the digital content, provides a learner-orient environment for the tutors and learners. The e-learning supports the construction of life-long virtual learning environments. In e-learning the learners uses a computer to learn a task, skill, or process. It is also referred to as computerbased training, internet-based learning, web-based training, and online learning. Today, elearning is extensively used on different educational levels such as academic courses, continuous education, company trainings, etc.

A subset of e-learning is M-learning, M-learning is mobile learning, which means learning using portable devices that allow the learner to learn in different environments and whilst on the move instead of being restricted to a classroom setting or tied to a desk. The term has grown enormously in popularity in the past few years, with the advent of handheld wireless devices such as iPads and tablets and increasingly sophisticated mobile phones.

The essential requirements for C-learning (classroom learning) are the building, teaching faculties, time duration for learning, hardware and software resources. Now a day's sometimes the teaching institute does not have enough classrooms, faculties/tutors, hardware and software. To make teaching and learning process time and cost effective the concept of e-learning is very useful. Thus, E-learning can be more effective than C-learning.

Simply we can say that E-learning is a new education concept which uses the technology to make possible people to learn $24 \times 7$ at anywhere. It is an electronically supported learning and teaching which provides digital communication through the internet and electronic devices such as computer, tablets, cell phones, PDAs, Laptops, iPads etc. It is used for online-training, the delivery of immediate information and guidance from the experts. In E-learning environments learners interact with learning materials, their instructors and other learners from various locations and often at various times using network technologies. E-learning improves the learning and teaching experience by the use of online communication tools.

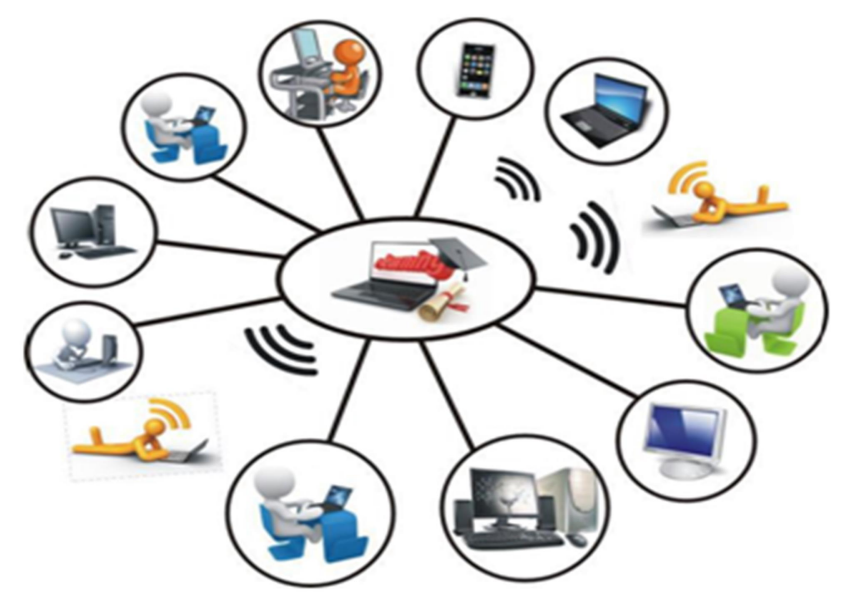

Figure 1. E-learning 
International Journal of Information Sciences and Techniques (IJIST) Vol.6, No.1/2, March 2016

Usually, e-learning systems are developed as distributed applications, but not limited to as shown in Figure 1. The architecture of an e-learning system, developed as a distributed application, includes a client application, an application server and a database server, beside the hardware to support it (client computer, communication infrastructure and servers). The client hardware could be a mobile device or a desktop computer. The client application can be a simple web browser or a dedicated application. ${ }^{[8]}$

\section{CATEGORIES OF E-LEARNING}

E-learning has two main categories. The categories are:

\subsection{Asynchronous E-learning}

In asynchronous e-learning, the communication between participants does not occur at the same time and learner can learn at anytime. The learning content is available at a Web server which is on cloud for learners all the time and on demand of the learner's workstation that will delivered from cloud. Due to its lower cost of development, reusable components and ease to the learner, now days it becomes more popular. This type of e-learning usually takes place via CD-ROMbased, Network-based, Intranet-based or Internet-based. It may include access to tutors through online bulletin boards, online discussion groups or e-mail.

\subsection{Synchronous E-learning:}

Synchronous training is that classes are conducted over the Internet with a live tutor. All tutors and learners are logs in at the same time and can communicate directly and virtually with each other, which allow people to interact with peers and experts. Learner can raise his/her cyber hand and even view the cyber whiteboard. This type of e-learning usually takes place via virtual classroom, audio or video conferencing, internet telephony, shared whiteboard, application sharing, live web casts, chat rooms or even two way live broadcasts to learners in a classroom.

Many education institutions do not have the resources and infrastructure needed to run top elearning solution. This is why Blackboard and Moodle, the biggest players in the field of elearning software, have now versions of the base applications that are cloud oriented ${ }^{[8]}$

\section{Cloud Computing}

The Cloud Computing environment ascends as a natural platform to provide support to ELearning systems. E-learning with the combination of cloud computing provides the concept of virtual teaching and learning process. Cloud computing is attractive technology for the teaching institutes with its dynamic scalability and usage of virtualized resources as a service through the Internet as shown in Figure 2.

According to NIST cloud computing means - "Cloud computing is a model for enabling ubiquitous, convenient, on-demand network access to a shared pool of configurable computing resources (e.g., networks, servers, storage, applications, and services) that can be rapidly provisioned and released with minimal management effort or service provider interaction. This cloud model is composed of five essential characteristics, three service models, and four deployment models." [4] 
International Journal of Information Sciences and Techniques (IJIST) Vol.6, No.1/2, March 2016

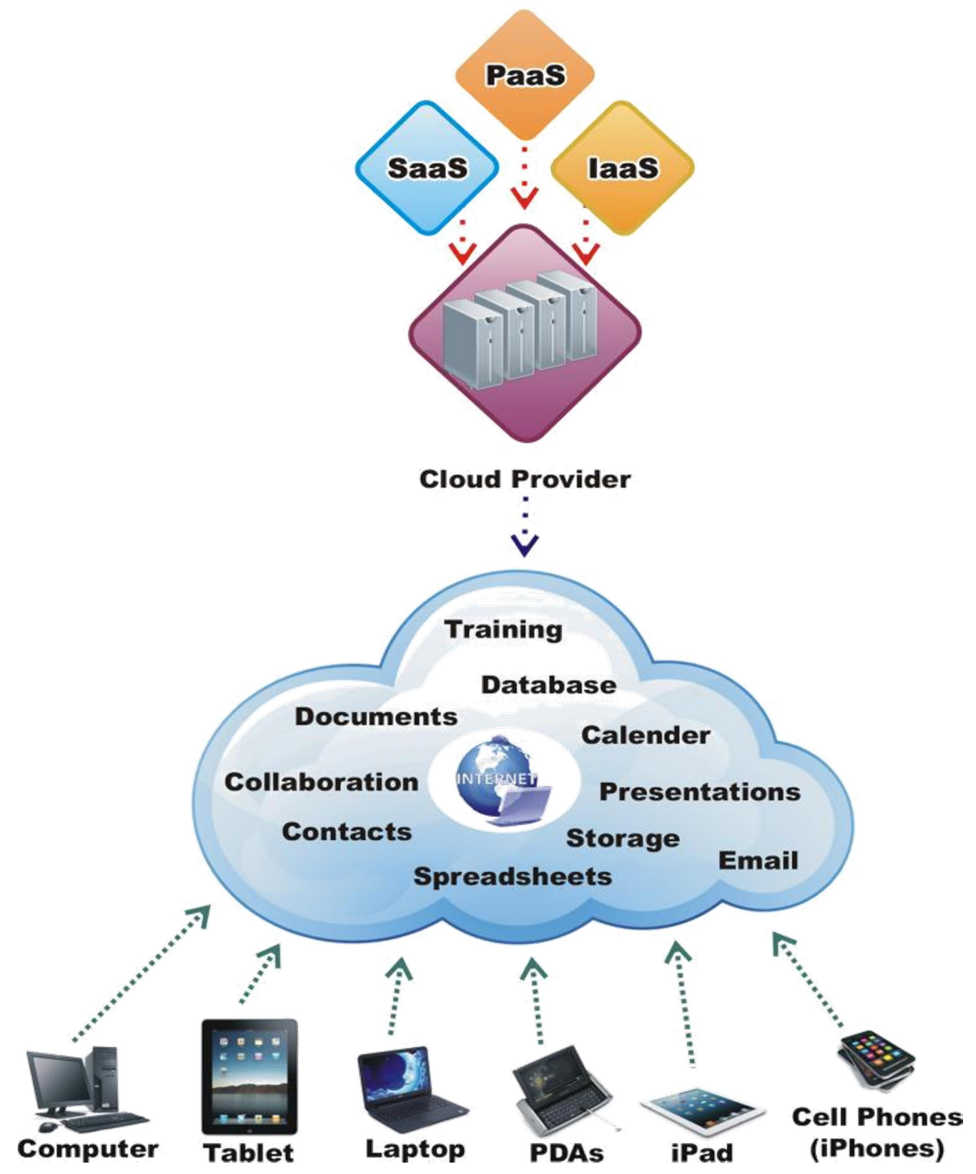

Figure 2. Cloud Computing

\section{The Cloud COMPuting LAYERS For THe SERVICE MOdelS}

There are three service models of cloud computing. They are shown in below Figure 3:

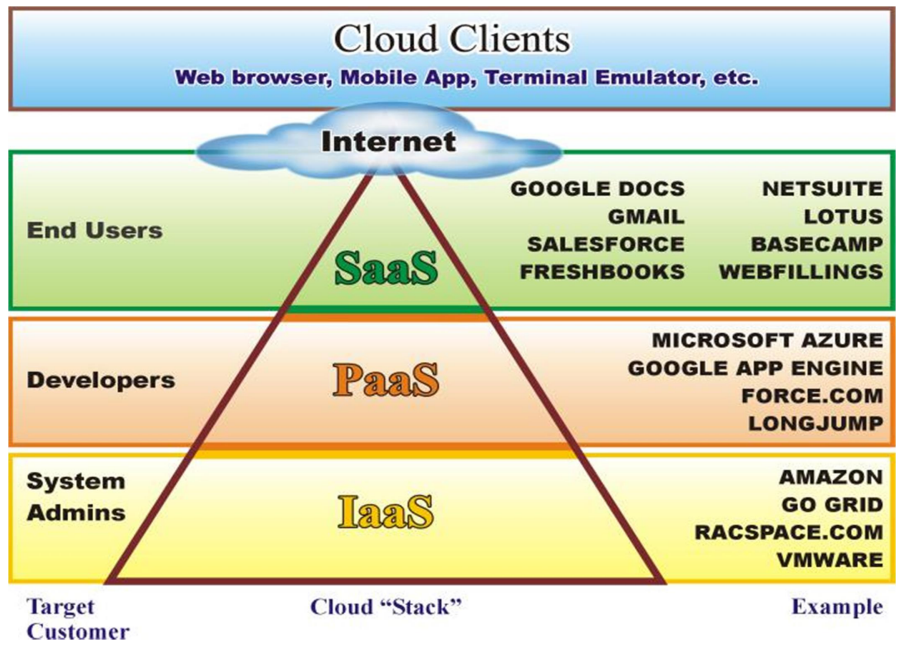

Figure 3. The Cloud Computing layers for the Service Models 
International Journal of Information Sciences and Techniques (IJIST) Vol.6, No.1/2, March 2016

\subsection{Software as a Service (SaaS)}

The level SaaS used to offer software as a service. This was one of the first implementations of Cloud services. In this model, software applications are offered as services on the Internet rather than as software packages to be purchased by individual customers. It has its origins in the host operations carried out by the Application Service Providers, from which some companies offered to others the applications known as Customer Relationship Managements ${ }^{[5]}$. The institute is free from up-gradation and licensing of software resources. This layer is used as the e-learning solution given by the provider. The capability provided to the end user is to use the provider's applications running on a cloud infrastructure. The applications are accessible from various client devices. The end user does not manage or control the underlying cloud infrastructure including network, servers, operating systems, storage, or even individual application capabilities, with the possible exception of limited user-specific application configuration settings ${ }^{[4]}$.

\subsection{Platform as a Service (PaaS)}

This level refers to offering services to support the entire application development lifecycle including design, implementation, debugging, testing, deployment, operation and support of Web applications and services on the Internet. In this manner, a PaaS provider does not provide the infrastructure directly, but making use of the services of an IaaS it presents the tools that a developer needs, having an indirect access to the IaaS services and, consequently, to the infrastructure $^{[6] .}$ A piece of software delivered as a service that allows development of 3rd party applications to "plug into" it. This layer used to develop an e-learning solution based on the provider's development interface.

\subsection{Infrastructure as a Service (IaaS)}

IaaS is the supply of hardware as a service, that is, servers, net technology, storage or computation, as well as basic characteristics such as Operating systems and virtualization of hardware resources ${ }^{[9]}$. Hardware resources such as storage, computing power such as CPU and memory and other IT infrastructure are offered as services to customers. This enables businesses to charge these resources rather than spending money to buy dedicated servers and networking equipment. This layer is uses an e-learning solution on the provider's infrastructure. The capability provided to the consumer is to provision processing, storage, networks, and other fundamental computing resources where the consumer is able to deploy and run arbitrary software, which can include operating systems and applications ${ }^{[4]}$.

The service model of a Cloud Computing layers as depicted in Figure 3 is usually common to most e-Learning approaches on the Cloud. In the first layer, it has the interface with the Cloud environment, which consists in several management subsystems for determining the current requirements of the user in terms of computational resources, being these the planner for the storage services, the management for distribution of the execution load among the virtual machines, a system administrator to monitor and to initiate activities of each layer, and a security component to ensure the privacy, recovery, integrity and security of user data and transactions, among others. The second layer represents the virtual machines implemented within the system. The provider supplies more than just infrastructure. For example, an integrated set of software with all the stuff that a developer needs to build applications, both for the developing and for the execution stages. Finally, the third layer includes all the physical architecture of the system. The 
International Journal of Information Sciences and Techniques (IJIST) Vol.6, No.1/2, March 2016

consumer does not manage or control the underlying cloud infrastructure but has control over operating systems, storage, and deployed applications; and possibly limited control of select networking components (e.g., host firewalls $)^{[4]}$.

There are many educational institutions that cannot afford investments on C-learning, therefore cloud computing is the finest solution, particularly in the institutes where the use of computers are more intensive and what can be done to increase the benefits of common applications for learners and tutors. Cloud computing for e-learning is an excellent alternative for academic institutes which are especially under budget shortage in order to build, host and operate their virtual learning community effectively without spending any more capital for the computers purchase software, licensing new software, power, cooling, servers, storages, network devices, technical team, maintenance team or do not have the resources and infrastructure needed to run elearning effectively ${ }^{[7]}$.

E-learning with cloud computing provides an environment where user only requires a computer or cell. Cloud computing facilitates the software, hardware and platform, so user can access the data on cloud any time and from any place, they can also interact with each other. There is no requirement of premises and there is no time duration for teaching. When we implement the cloud computing for e-learning there are essential characteristics are On-demand self-service, Broad network access, Resource pooling, Rapid elasticity, Measured service, etc.

\section{KEY BENEFITS OF USING CLOUD COMPUTING FOR E-LEARNING}

The various advantages are

\subsection{Benefits of cloud computing for e-Learning to the Learner, Tutor and Institute}

- Easy and Quick accessibility Available to anyone 24/7.

- Reduce time and cost.

- Modular.

- Wide participation.

- Accommodating different learning styles and levels.

- A positive impact on learners, tutors, as well as the educational system as a whole.

- Effective technologies use many evidence-based strategies (e.g., immediate feedback, online content management, frequent testing and assignements, etc.).

- Proof of completion and certification, essential elements of training initiatives, can be automated.

\subsection{Benefits of cloud computing for e-Learning to the Learner}

- Learning 24/7, anywhere with access to a computer and Internet connection; it reduces the cost and time of travelling.

- Self paced, means learn with their own speed, so it improves the satisfaction and reduce the level of stress.

- Student motivation and Confidence that refresher or quick reference materials are available reduces burden of responsibility of mastery.

- More opportunities for distance extended learning. 
International Journal of Information Sciences and Techniques (IJIST) Vol.6, No.1/2, March 2016

- Easy-to-access course materials, which is provided by tutor.

- Students may have the option to select learning materials that meets their level of knowledge and interest.

- Re-useable learning materials, so learners can make assignment and exam preparation.

- Enables to complete their course conveniently at off-hours from home.

- Skip the topics, which they already understand and jump to new topic; in this manner the total learning time, are saved.

- Take online course and take the online exams.

- Submit their assignments or projects to their tutors from anywhere.

- Updating of their assignments or projects is possible, if needed.

- It's discreet, not everybody feels comfortable learning in a large group, especially if they find something hard to understand. So each individual to tackle the subject at their own pace.

- Learn on a global scale.

- Interactivity engages learners, pushing them rather than pulling them through training.

- Class work can be scheduled around work and family.

- Flexibility to join discussions in the bulletin board threaded discussion areas at any hour, or visit with classmates and instructors remotely in chat rooms.

- Accommodate different learning style.

- Facilitate learning through a variety of activities.

- Develops knowledge of the Internet and computers skills that will help learners throughout their lives and careers.

- Access to variety of learning resources.

- Immediacy to information.

- User can run the applications from cloud through their PC or mobile phones having minimum configuration with internet connectivity. The data is stored and accessed through cloud; therefore user need not spend more money for large memory for data storage in local machines. Software's are automatically updated in cloud.

\subsection{Benefits of cloud computing for e-Learning to the Tutor}

- Reduced overall cost by reduction of time spent in travelling, lodging and food.

- Teaching times reduced as an average of 40 to 60 percent.

- Allow to complete the course as per tutor choice.

- Self paced, means teach with their own speed and also as per tutors' interest.

- Easy to distribute the course materials.

- Re-useable learning materials.

- Online learning materials are Updateable, so easy to edit, to update and to review.

- Online tests, quiz, homework, projects and assignments distribution and evaluation is possible at any time.

- To get the immediate feedback of learner as well as to send feedback of progress to their learners.

- Trackable results of learner.

- Consistent delivery of content is possible.

- Expert knowledge is communicated by same interested/taken subject tutors.

- Easy accessing various resources. 
International Journal of Information Sciences and Techniques (IJIST) Vol.6, No.1/2, March 2016

- Easy to Deal with content management.

- Easy to communicate with learners (forums).

\subsection{Benefits of cloud computing for e-Learning to the Institute}

- No cost of institute building's rent because learning is online.

- Easy to track and prove progress for your tutors and learners.

- The institute is free from the management of different time schedule.

- Reduces overall costs of education institutes, which includes the cost of travel, lodging, meals, tutors salaries, the west of employee work time, rent of room/building, production and distribution of the course materials.

- Centralized data storage - losing a cloud client is no longer a major incident while the main part of the applications and data is stored into the cloud so a new client can be connected very fast.

\section{CONCLUSiOnS}

In the current economical crisis and being faced by rising desires, teaching institutes are facing problems in providing necessary IT support for educational activities. The objective of this paper is to provide educational environment which is based on reusing the existing web tools, techniques, and services to provide browser based application. Cloud computing into an eLearning platform allows the integration of different e-Learning standards to enhance interoperability of learning objects. The concept e-learning with cloud computing provides a cost effective solution to academic institutions for their tutors and learners. Cloud computing is rising swiftly, with applications in almost all area, especially in education. There are some limitations of e-learning are lack of face-to-face interaction with the tutor and the learners, reduced social and cultural interaction, etc. There are many benefits from using the cloud computing for e-learning systems. Also, there are some disadvantages that have to be taken into account. But still benefits are more than the limitations. Using cloud computing for e-learning solutions influences the way the e-learning software projects are managed; There are specific tasks that deal with finding providers for cloud computing, depending on the requirements (infrastructure, platform or services) also, the cost and risk management influences the way the e-learning solutions based on cloud computing are managed [8]. Currently the research society has suspected that an e-learning is the next generation of Education Learning Mechanisms. In this paper we tried to prove that cloud computing changed E-Learning future systems. A wide world of knowledge and tools now is available to tutors and learners through cloud based services all the time and accessed from anywhere, from any device. The study summarized the main advantages, which include flexibility, convenience, easy accessibility, consistency and its repeatability.

\section{ACKNOWLEDGEMENTS}

The authors thank MCA Department of Charotar University of Science and Technology (CHARUSAT) for providing required resources to accomplish this research survey. 
International Journal of Information Sciences and Techniques (IJIST) Vol.6, No.1/2, March 2016

\section{REFERENCES}

[1] Richey, R.C., (2008) “AECT Definitions of the Field. TechTrends", Reflections on the 2008. 52(1) 24-25.

[2] Bernard luskin, (2012) "Think "Exciting": E-Learning and the Big "E", Retrieved 7 December 2012.

[3] Mayer R., Clark R., (2011) "E-Learning and the Science of Instruction: Proven Guidelines for Consumers and Designers of Multimedia Learning", 3rd edition 2011.

[4] Peter Mell, Timothy Grance. (2011) "The NIST Definition of Cloud Computing". National Institute of Standards and Technology. Retrieved 24 July 2011. [Special Publication 800-145].

[5] Duer W., (2003) CRM, Customer Relationship Management, MP editions.

[6] Hurwitz J., Bloor R., Kaufman M., Halper F., (2010) Cloud Computing for Dummies, Wiley.

[7] Behrend, T. S., Wiebe, E. N., London, J. E., \& Johnson, E. C., (2011) "Cloud computing adoption and usage in community colleges. Behaviour \& Information Technology”, 30(2), 231-240, .

[8] Paul POCATIL, (2010) "Cloud Computing Benefits for E-learning Solutions", Oeconomics of Knowledge, Vol. 2, Issue 1, 1Q 2010, pp. 9-14.

[9] A. Fern'andez, D. Peralta, F. Herrera, and J.M. Ben'itez, (2012) "An Overview of E-Learning in Cloud Computing", Workshop on LTEC 2012, AISC 173, pp. 35-46.

[10] N. S. Abu El-Ala, W. A. Awad and H. M. El-Bakry, (2012) " Cloud Computing for Solving ELearning Problems", International Journal of Advanced Computer Science and Applications (IJACSA), Vol. 3, No. 12, pp. 135-137.

[11] Paul Pocatilu, Felician Alecu, Marius Vetrici, (2010) "Measuring the Efficiency of Cloud Computing for E-learning Systems", WSEAS TRANSACTIONS on COMPUTERS, Vol. 9, Issue 1, January 2010, pp 42-51.

[12] Valérie MONFORT, Maha KHEMAJA, Nouha AMMARI, Fayssal FEHLI, (2010) "Using SaaS and Cloud computing For "On Demand" E Learning Services:Application to Navigation and Fishing Simulator", 10th IEEE International Conference on Advanced Learning Technologies, pp 663-665.

[13] Mohssen M. Alabbadi, (2011) "Cloud Computing for Education and Learning:Education and Learning as a Service (ELaaS)",14th International Conference on Interactive Collaborative Learning (ICL2011) 11th International Conference Virtual University (vu'11), 21-23 September 2011, pp 589594.

[14] Aida Ghazizadeh, (2012)"Cloud Computing Benefits And Architecture In E-Learning", Seventh IEEE International Conference on Wireless, Mobile and Ubiquitous Technology in Education, pp199201.

[15] Majid Shirzad, Ali Hoseinpanah, Mehdi Ahmadipour, Hojat Rahimi, (2012) "E-Learning Based on Cloud Computing", Intemational of Cloud Computing, Technologies, Applications \& Management, pp 214-218. 
International Journal of Information Sciences and Techniques (IJIST) Vol.6, No.1/2, March 2016

[16] Nungki Selviandro, Mira Suryani, Zainal A. Hasibuan, (2014) "Enhancing the Implementation of Cloud-Based Open Learning with E-Learning Personalization", ICACT Transactions on Advanced Communications Technology (TACT), Vol. 3, Issue 4, July 2014, pp 472-479.

[17] Mohammed Al-Zoube, (2009) "E-Learning on the Cloud", International Arab Journal of eTechnology, Vol. 1, No. 2, June 2009, pp 58-64.

[18] Utpal Jyoti Bora, Majidul Ahmed, (2013) "E-Learning using Cloud Computing", International Journal of Science and Modern Engineering (IJISME), Vol.-1, Issue-2, January 2013, pp 9-13.

\section{AUTHORS}

Mansi Bosamia received B.C.A. and M.C.A. Degree from Bhavnagar University, India. Now she is an Assistant Professor, Smt. Chandaben Mohanbhai Patel Institute of Computer Applications - Changa, India. She is pursuing Ph. D. and her main research areas are Data Structures and Networking. She has published and presented 3 papers in National and International Conferences. She also published books named "Computer Algorithms using C" at YS books International, New Delhi and "Illustrating Data Structures through C" at Creative Crows Publishers LLP, New Delhi.

Atul Patel received Bachelors degree in Science (Electronics), M.C.A. Degree from Gujarat University, India. M. Phil. (Computer Science) Degree from Madurai Kamraj University, India. Now he is a Principal and Dean, Smt. Chandaben Mohanbhai Patel Institute of Computer Applications - Changa, India. He has received Ph. D degree in wireless ad-hoc network from Sardar Patel University. His main research areas are wireless communication and Network Security.
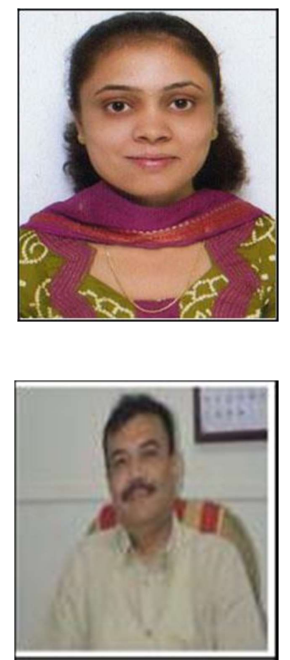